\title{
JARGON PADA KOMUNITAS VAPE DI CINERE
}

\author{
Restu Susprestrianto \\ Program Studi Sastra Indonesia, Universitas Pamulang \\ Email:restubotax@yahoo.com
}

\begin{abstract}
ABSTRAK
Penelitian ini bertujuan untuk mendeskripsikan variasi bahasa jargon yang digunakan oleh komunitas Vape di Cinere. Penelitian ini menggunakan metode deskriptif kualitatif. Penelitian ini terfokus pada bentuk jargon, makna jargon dan fungsi jargon. Data yang dikumpulkan dengan menggunakan teknik simak/sadap sebagai teknik dasarnya dan teknik lanjutannya menggunakan teknik Simak Bebas Libat Cakap (SBLC), dan wawancara agar data yang sudah didapat lebih akurat dan bersifat objektif. Hasil penelitian menunjukan bahwa terdapat 31 jargon dalam bentuk kata. Ditemukan 19 jargon bentuk kata benda (nomina). Di antaranya: Atomizer, Bane, Barrel, Cartomizer, Cloud, Fralien, Gunk, Kanthal, Lanyard, Mesh, Mod, Nic, Pod, Vape, Vapers, Vapor, Vaporista, Vaporizer, Wick. Ditemukan 7 kata kerja (Verba). Di antaranya: Coiling, Firing, Garuk, Puff, Spitback, Vaping, Wicking. Ditemukan 5 kata sifat (Ajektifa). Di antaranya: Bold, Clone, Creamy, Freebase, Oten. Terdapat 7 jargon dalam bentuk frasa. Ditemukan 6 frasa Nomina di antaranya: Cloud Chase, Dry Hit, Fused Clapton, Ghost Taste, Salt Nic, Vape Tonque. Ditemukan 1 frasa Verba yaitu Dry Burn. Ditemukan 43 makna jargon yang mengandung makna istilah. Di antaranya: Atomizer, Bane, Barrel, Bold, Cartomizer, Clone, Coiling, Creamy, Firing, Fralien, Freebase, Gunk, Kanthal, Lanyard, Mesh, Mod, Nic, Oten, Pod, Puff, Spitback, Vape, Vapers, Vaping, Vapor, Vaporista, Vaporizer, Wick, Wicking, Cloud Chase, Dry Burn, Dry Hit, Fused Clapton, Ghost Taste, Salt Nic, Vape Tonque, DTL (Direct To Lungs), MTL (Mouth To Lungs), (Rebuildable Atomizer), RDA (Rebuildable Dripping Atomizer), RDTA (Rebuildable Dripping Tank Atomizer), RTA (Rebuildable Tank Atomizer), TH (Throat Hit). Ditemukan 1 jargon yang mengandung makna leksikal yaitu Cloud dan 2 jargon yang mengandung makna kontekstual di antaranya: Garuk, PSK/Paket Siap Kebul. Fungsi pengunaan jargon pada komunitas Vape di Cinere terdiri dari 3 fungsi, yaitu fungsi instrumental, fungsi refresentasi dan fungsi heuristik.
\end{abstract}

Kata Kunci : Sosiolinguistik, jargon, makna jargon dan fungsi jargon.

\begin{abstract}
This study aims to describe the variations in the jargon language used by the Vape community in Cinere. This research uses descriptive qualitative method. This research focuses on the form of jargon, the meaning of the jargon and the function of the jargon. The data was collected using listening / tapping techniques as a basic technique and follow-up techniques using the Speaking Free Speaking Technique (SBLC), and interviews so that the data obtained was more accurate and objective. The results showed that there were 31 jargon in the form of words. Found 19 jargon form noun (noun). Among them: Atomizer, Bane, Barrel, Cartomizer, Cloud, Fralien, Gunk, Kanthal, Lanyard, Mesh, Mod, Nic, Pod, Vape, Vapers, Vapor, Vaporista, Vaporizer, Wick. Found 7 verbs (Verbs). Among them: Coiling, Firing, Scratching, Puff, Spitback, Vaping, Wicking. Found 5 adjectives (Ajectivea). Among them: Bold, Clone, Creamy, Freebase, Oten. There are 7 jargon in the form of phrases. Found 6 noun phrases including: Cloud Chase, Dry Hit, Fused Clapton, Ghost Taste, Salt Nic, Vape Tonque. Found 1 Verb phrase, Dry Burn. There are 43 jargon meanings that contain the meaning of the term. Among them: Atomizer, Bane, Barrel, Bold, Cartomizer, Clone, Coiling, Creamy, Firing, Fralien, Freebase, Gunk, Kanthal, Lanyard, Mesh, Mod, Nic, Oten, Pod, Puff, Spitback, Vape, Vapers, Vaping, Steam, Vaporista, Vaporizer, Wick, Wicking, Cloud Chase, Dry Burn, Dry Hit, Fused Clapton, Ghost Taste, Salt Nic, Vape Tonque, DTL (Direct To Lungs), MTL (Mouth To Lungs), (Rebuildable Atomizer), RDA (Rebuildable Dripping Atomizer), RDTA (Rebuildable Dripping Tank Atomizer), RTA (Rebuildable Tank Atomizer), TH (Throat Hit). Found 1 jargon that contains lexical meaning, namely Cloud and 2 jargon that contains contextual meaning, among others: Garuk, PSK / Paket Siap Kebul. The function of using jargon in the Vape community in Cinere consists of 3 functions, namely the instrumental function, the presentation function, and the heuristic function.
\end{abstract}

Keywords: Sociolinguistics, Jargon, Meaning of Jargon and Function of Jargon. 


\section{PENDAHULUAN}

Dalam keberagaman masyarakat dan latar belakang manusia sebagai individu menimbulkan berbagai variasi bahasa yang digunakan di dalam interaksi sosial. Suatu kelompok yang ada di tengahtengah masyarakat pasti mempunyai bahasa tertentu yang merupakan lambang identitas dari kelompoknya, yang ditandai dengan kekhasan perilaku dan pemakaian bahasa.

Kekhasan inilah yang membedakan dari kelompok lain. Kekhasan ini hanya dipahami oleh mereka dalam kegiatan yang mereka lakukan bersama. Salah satunya adalah yang dipakai oleh komunitas Vape. Bahasa yang dipakai oleh komunitas Vape sangat beragam. Salah satu ragam bahasa yang digunakan adalah dalam bentuk jargon.

Chaer \& Agustina, (2010: 68) mengartikan jargon sebagai variasi sosial yang digunakan secara terbatas oleh kelompok-kelompok sosial tertentu. Jargon berbentuk ungkapan-ungkapan yang seringkali tidak dapat dipahami oleh masyarakat umum atau masyarakat di luar kelompoknya. Namun, ungkapan tersebut tidak bersifat rahasia.

Jargon sebuah fenomena kebahasaan sangat menarik dan unik, itu dikarenakan melambangkan suatu kekhasan instansi atau komunitas-komunitas. Jargon sangat berkembang di kalangan masyarakat, terutama pada sebuah instansi pemerintah yang menggunakan jargon dalam lingkungan pekerjaan untuk memudahkan berinteraksi atau dalam sebuah perkumpulan masyarakat sosial. Perkembangan tersebut sangat pesat terlebih dengan adanya berbagai media yang mendukung. Sebagai contoh, penggunaan jargon pada instansi perkeretaapian, dinas perhubungan, SATPOL PP, dan komunitas-komunitas yang ada di indonesia, seperti komunitas fotografer, komunitas KASKUS, komunitas motor CB, komunitas Vape dan masih banyak lagi.

Setiap kehidupan di masyarakat, ada beberapa anggota kelompok yang menggunakan bahasa atau istilah tertentu, yang kadang kala kurang dipahami oleh orang lain. Bahasa itu sering digunakan antar anggota kelompok yang secara tidak langsung dan berusaha mengembalikan citra baik dikalangan masyarakat. membuat mereka berbeda dengan yang lainnya. Salah satu yang menggunakan bahasa tertentu adalah komunitas Vape di Cinere.

Penggunaan jargon pada komunitas Vape di Cinere sangat menarik untuk diteliti. Karena semenjak penulis menggunakan Vape, penulis melihat ada banyak istilah atau jargon di dalam komunitas ini yang menarik untuk dibahas. Di dalam komunitas Vape di Cinere banyak sekali istilahistilah yang tidak diketahui oleh masyarakat pada umumnya dan hanya diketahui oleh anggota komunitas Vape atau masyarakat umum yang memang menggunakan Vape juga.

Berdasarkan observasi yang penulis lakukan, bahasa yang dipakai oleh komunitas Vape cenderung menggunakan kosakata yang tidak biasa, singkat, dan terkesan berbeda dari bahasa yang dipakai pada umumnya dan banyak mengadopsi dari bahasa asing yaitu bahasa Inggris. Namun demikian, kosakata tersebut tetap dipahami oleh anggota komunitas Vape. Kosakata yang mereka pakai pada umumnya mengacu pada kode yang telah dibuat oleh komunitas setempat. 
Berikut adalah contoh percakapan atau tuturan yang mengandung jargon dan maknanya yang sering digunakan oleh komunitas Vape di Cinere :

(01) : Om, Mod sama Pod lo sepertinya Clone nih!

(02) : ah yang bener, Vaporistanya bilang Oten kok.

Pada percakapan tersebut, terdapat lima buah jargon dalam bentuk kata yang digunakan oleh komunitas Vape yaitu Mod, Pod, Clone, Vaporista dan Oten.

Dalam dunia Vape Mod adalah alat yang digunakan sebagai media pemanas coil dan atomizer, berbentuk tabung atau box. Jargon Pod adalah alat yang digunakan sebagai media pemanas coil dan atomizer, berbentuk stick dan lebih kecil dari Mod. Jargon Clone adalah barang tiruan atau palsu pada perangkat Vape, jargon Vaporista adalah karyawan di sebuah toko perlengkapan Vape yang bertugas melayani pelanggan atas segala kebutuhan Vape. Jargon Oten berasal dari kata Authentic yang artinya perlengkapan vape yang asli. Kelima jargon dalam bentuk kata tersebut merupakan jargon yang biasa digunakan oleh komunitas Vape dalam aktifitasnya.

Penggunaan jargon oleh komunitas Vape pada percakapan dan tuturan tersebut tidak bersifat rahasia, tetapi masyarakat di luar komunitas pengguna jargon tersebut tidak dapat memahami istilah tersebut. Hal ini disebabkan oleh makna dari kata-kata yang mereka gunakan berbeda dengan makna sesungguhnya. Berdasarkan penjelasan tersebut, hal ini menarik untuk diteliti dan dikaji lebih lanjut.

Penulis hanya menekankan penelitian pada bentuk, makna dan fungsi jargon yang dipakai oleh komunitas Vape di Cinere. Apakah bahasa yang digunakan seluruhnya menggunakan jargon, atau hanya sewaktu-waktu tertentu saja. Dalam komunitas Vape di Cinere, bentuk kosakata yang mereka gunakan beraneka ragam serta memiliki kekhasan yang mewakili kelompoknya. Sedangkan pisau analisis yang digunakan adalah kajian sosiolinguistik.

\section{TEORI DAN METODOLOGI}

Penelitian ini menggunakan metode deskriptif kualitatif. Penelitian deskriptif kualitatif adalah penggambaran secara menyeluruh tentang bentuk, makna dan fungsi jargon. Hal ini sejalan dengan pendapat Bogdan dan Taylor (1975) (dalam Moleong, 2002) yang menyatakan "metodologi kualitatif" sebagai prosedur penelitian yang menghasilkan data deskriptif berupa kata-kata tertulis atau lisan dari orang-orang dan perilaku yang dapat diamati.

Penelitian kualitatif harus mempertimbangkan metodologi kualitatif itu sendiri. Metodologi kualitatif merupakan prosedur yang menghasilkan data deskriptif berupa data tertulis atau lisan di masyarakat bahasa (Djajasudarma, 2006:11). Lebih lanjut dijelaskan bahwa pendekatan kualitatif yang menggunakan data lisan suatu bahasa memerlukan informan. Pendekatan yang melibatkan masyarakat bahasa ini diarahkan pada latar dan individu yang bersangkutan secara holistik sebagai bagian dari satu kesatuan yang utuh. Oleh karena itu, dalam penelitian bahasa jumlah informan tidak ditentukan jumlahnya. Dengan kata lain, jumlah informannya ditentukan sesuai dengan keperluan penelitian. 
Metode analisis data dalam penelitian ini dilakukan dengan menggunakan metode padan dan agih. Metode padan adalah metode analisis bahasa yang penentunya tidak menjadi bagian dari bahasa (langue) yang bersangkutan (Sudaryanto, 1993: 13). Penggunaan metode ini didasarkan pada asumsi bahwa bahasa yang diteliti memang sudah memiliki hubungan dengan hal-hal di luar bahasa yang bersangkutan (Sudaryanto, 1993:14). Metode padan yang digunakan dalam penelitian ini adalah padan referensial karena alat penentunya adalah kenyataan yang ditunjuk oleh bahasa. Metode padan referensial ini digunakan untuk menganalisis makna dan fungsi jargon komunitas vape.

\section{TEMUAN DAN PEMBAHASAN}

Penulis mendeskripsikan hasil penelitian dan pembahasan terhadap penggunaan Jargon Pada Komunitas Vape Di Cinere, berupa bentuk jargon, makna jargon serta fungsi jargon pada komunitas Vape di Cinere. Jumlah data jargon pada komunitas Vape di Cinere yang terkumpul sebanyak 46 jargon. Data yang diperoleh secara langsung tersebut didapat dengan cara merekam secara langsung pada percakapan dan wawancara komunitas Vape di Cinere dengan menggunakan hand phone (HP) sebagai alatnya. Setelah data rekaman terkumpul, dilanjutkan dengan pencatatan hasil rekaman sebagai data dalam penelitian. Selanjutnya data yang telah diperoleh ditranskripsikan pada lembar pencatatan. Data jargon yang terkumpul dalam lembar pencatatan terdapat 46 jargon. Dalam data ini ditemukan sebanyak 31 bentuk jargon kata seperti jargon Atomizer, Bane, Barrel, Bold, Cartomizer, Clone, Cloud, Coiling, Creamy, Firing, Fralien, Freebase, Garuk, Gunk, Kanthal, Lanyard, Mesh, Mod, Nic, Oten, Pod, Puff, Spitback, Vape, Vapers, Vaping, Vapor, Vaporista, Vaporizer, Wick, Wicking. Kemudian bentuk jargon frasa ditemukan sebanyak 7 seperti. Cloud Chase, Dry Burn, Dry Hit, Fused Clapton, Ghost Taste, Salt Nic, Vape Tonque. Selanjutnya bentuk jargon yang berasal dari singkatan ditemukan sebanyak 8 seperti jargon DTL/Direct To Lungs, MTL/Mouth To Lungs, PSK/Paket Siap Kebul, RBA/Rebuildable Atomizer, RDA/Rebuildable Dripping Atomizer, RDTA/Rebuildable Dripping Tank Atomizer, RTA/Rebuildable Tank Atomizer, TH/Throat Hit.

\section{Berikut jargon dalam bentuk kata :}

\begin{tabular}{|l|c|l|}
\hline No & Jargon dalam bentuk kata & \multicolumn{1}{|c|}{ Kelas Kata } \\
\hline 1. & Atomizer & Kata Benda (Nomina) \\
\hline 2. & Bane & Kata Benda (Nomina) \\
\hline 3. & Barrel & Kata Benda (Nomina) \\
\hline 4. & Bold & Kata Sifat (Ajektifa) \\
\hline $\mathbf{5 .}$ & Cartomizer & Kata Benda (Nomina) \\
\hline
\end{tabular}




\begin{tabular}{|c|c|c|}
\hline 6. & Clone & Kata Sifat (Ajektifa) \\
\hline 7. & Cloud & Kata Benda (Nomina) \\
\hline 8. & Coiling & Kata Kerja (Verba) \\
\hline 9. & Creamy & Kata Sifat (Ajektifa) \\
\hline 10. & Firing & Kata Kerja (Verba) \\
\hline 11. & Fralien & Kata Benda (Nomina) \\
\hline 12. & Freebase & Kata Sifat (Ajektifa) \\
\hline 13. & Garuk & Kata Kerja (Verba) \\
\hline 14. & Gunk & Kata Benda (Nomina) \\
\hline 15. & Kanthal & Kata Benda (Nomina) \\
\hline 16. & Lanyard & Kata Benda (Nomina) \\
\hline 17. & Mesh & Kata Benda (Nomina) \\
\hline 18. & Mod & Kata Benda (Nomina) \\
\hline 19. & $\mathrm{Nic}$ & Kata Benda (Nomina) \\
\hline 20. & Oten & Kata Sifat (Ajektifa) \\
\hline 21. & Pod & Kata Benda (Nomina) \\
\hline 22. & Puff & Kata Kerja (Verba) \\
\hline 23. & Spitback & Kata Kerja (Verba) \\
\hline 24. & Vape & Kata Benda (Nomina) \\
\hline 25. & Vapers & Kata Benda (Nomina) \\
\hline 26. & Vaping & Kata Kerja (Verba) \\
\hline 27. & Vapor & Kata Benda (Nomina) \\
\hline 28. & Vaporista & Kata Benda (Nomina) \\
\hline 29. & Vaporizer & Kata Benda (Nomina) \\
\hline
\end{tabular}




\begin{tabular}{|l|l|l|}
\hline 30. & Wick & Kata Benda (Nomina) \\
\hline 31. & Wicking & Kata Kerja (Verba) \\
\hline
\end{tabular}

\section{Berikut jargon dalam bentuk frasa :}

\begin{tabular}{|l|c|c|}
\hline No & Jargon dalam bentuk Frasa & Jenis Frasa \\
\hline 1. & Cloud Chase & Frasa Nomina \\
\hline 2. & Dry Burn & Frasa Verba \\
\hline 3. & Dry Hit & Frasa Nomina \\
\hline 4. & Fused Clapton & Frasa Nomina \\
\hline $\mathbf{5 .}$ & Ghost Taste & Frasa Nomina \\
\hline 6. & Salt Nic & Frasa Nomina \\
\hline 7. & Vape Tonque & Frasa Nomina \\
\hline
\end{tabular}

Berikut jargon dalam bentuk singkatan :

\begin{tabular}{|l|c|}
\hline No & Jargon dalam bentuk Singkatan \\
\hline $\mathbf{1 .}$ & DTL (Direct To Lungs) \\
\hline $\mathbf{2 .}$ & MTL (Mouth To Lungs) \\
\hline 3. & PSK (Paket Siap Kebul) \\
\hline 4. & RBA (Rebuildable Atomizer) \\
\hline $\mathbf{5 .}$ & RDA (Rebuildable Dripping Atomizer) \\
\hline 6. & RDTA (Rebuildable Dripping Tank Atomizer) \\
\hline 7. & RTA (Rebuildable Tank Atomizer) \\
\hline 8. & TH (Throat Hit) \\
\hline
\end{tabular}

Makna jargon dalam komunitas Vape di Cinere 


\begin{tabular}{|c|c|c|c|}
\hline No & Jargon/Istilah & Makna Jargon & Jenis Makna \\
\hline 1. & Atomizer & $\begin{array}{l}\text { Bagian dari vaporizer tempat coil dan kapas } \\
\text { yang telah ditetesi liquid dipanaskan } \\
\text { sehingga menciptakan uap untuk diisap. }\end{array}$ & Makna Istilah \\
\hline 2. & Bane & $\begin{array}{l}\text { Salah satu trick dalam vaping, menghirup } \\
\text { uap dari mulut ke hidung. }\end{array}$ & Makna Istilah \\
\hline 3. & Barrel & $\begin{array}{l}\text { Dinding sisi luar RDA yang terdapat lubang } \\
\text { airflow. }\end{array}$ & Makna Istilah \\
\hline 4. & Bold & Ketebalan Uap yang keluar saat vaping. & Makna Istilah \\
\hline 5. & Cartomizer & $\begin{array}{l}\text { Bagian dari vaporizer yang } \\
\text { mengkombinasikan antara cartridge dengan } \\
\text { atomizer, yang dipanaskan bersentuhan } \\
\text { langsung dengan komponen pemanas. }\end{array}$ & Makna Istilah \\
\hline
\end{tabular}

\section{Fungsi penggunaan jargon dalam komunitas Vape di Cinere}

\begin{tabular}{|c|c|c|}
\hline No & Jargon Dalam Bentuk Tuturan & Fungsi \\
\hline 1. & $\begin{array}{l}\text { Ganti om Atomizernya sama yang premade, } \\
\text { biar ga repot ganti coil sama kapas. }\end{array}$ & $\begin{array}{l}\text { Fungsi instrumental } \\
\text { (Menyampaikan anjuran) }\end{array}$ \\
\hline 2. & Ajarin gua trick ngeBane dong om? & $\begin{array}{c}\text { Fungsi heuristik } \\
\text { (Menyampaikan pertanyaan) }\end{array}$ \\
\hline 3. & $\begin{array}{l}\text { Udah tau belum, kalo dead rabbit ngeluarin } \\
\text { RDA baru. Keren loh Barrelnya bisa muter } \\
\text { sesuai keinginan kita. }\end{array}$ & $\begin{array}{c}\text { Fungsi refresentasi } \\
\text { (Menyampaikan informasi) }\end{array}$ \\
\hline 4. & $\begin{array}{l}\text { Coba deh lo pake liquid yang rasio PG } 70 \\
\text { VG } 30 \text { biar cloudnya lebih Bold. }\end{array}$ & $\begin{array}{l}\text { Fungsi instrumental } \\
\text { (Menyampaikan anjuran) }\end{array}$ \\
\hline 5. & $\begin{array}{l}\text { kalo mau simple pake Cartomizer aja om, } \\
\text { bisa keliatan sisa liquidnya. }\end{array}$ & $\begin{array}{l}\text { Fungsi instrumental } \\
\text { (Menyampaikan anjuran) }\end{array}$ \\
\hline
\end{tabular}




\section{KESIMPULAN DAN SARAN}

Berdasarkan pembahasan yang diuraikan pada Bab IV, dapat disimpulkan bahwa bentuk jargon pada komunitas Vape di Cinere terdiri dari jargon kata, jargon frasa dan jargon yang berasal dari singkatan/akronim. Bentuk jargon kata ditemukan sebanyak 31 di antaranya Atomizer, Bane, Barrel, Bold, Cartomizer, Clone, Cloud, Coiling, Creamy, Firing, Fralien, Freebase, Garuk, Gunk, Kanthal, Lanyard, Mesh, Mod, Nic, Oten, Pod, Puff, Spitback, Vape, Vapers, Vaping, Vapor, Vaporista, Vaporizer, Wick, Wicking. Kemudian bentuk jargon frasa ditemukan sebanyak 7 di antaranya Cloud Chase, Dry Burn, Dry Hit, Fused Clapton, Ghost Taste, Salt Nic, Vape Tonque. Selanjutnya bentuk jargon yang berasal dari singkatan/akronim ditemukan sebanyak 8 di antaranya DTL/Direct To Lungs, MTL/Mouth To Lungs, PSK/Paket Siap Kebul, RBA/Rebuildable Atomizer, RDA/Rebuildable Dripping Atomizer, RDTA/Rebuildable Dripping Tank Atomizer, RTA/Rebuildable Tank Atomizer, TH/Throat Hit.

Makna jargon pada komunitas Vape di Cinere ditemukan 43 jargon mengandung makna istilah di antaranya Atomizer, Bane, Barrel, Bold, Cartomizer, Clone, Coiling, Creamy, Firing, Fralien, Freebase, Gunk, Kanthal, Lanyard, Mesh, Mod, Nic, Oten, Pod, Puff, Spitback, Vape, Vapers, Vaping, Vapor, Vaporista, Vaporizer, Wick, Wicking, Cloud Chase, Dry Burn, Dry Hit, Fused Clapton, Ghost Taste, Salt Nic, Vape Tonque, DTL (Direct To Lungs), MTL (Mouth To Lungs), (Rebuildable Atomizer), RDA (Rebuildable Dripping Atomizer), RDTA (Rebuildable Dripping Tank Atomizer), RTA (Rebuildable Tank Atomizer), TH (Throat Hit). Ditemukan 1 jargon yang mengandung makna leksikal yaitu Cloud. Ditemukan 2 jargon yang mengandung makna kontekstual di antaranya Garuk, PSK/Paket Siap Kebul.

Penggunaan jargon pada komunitas Vape di Cinere berfungsi untuk mempermudah berkomunikasi antarsesama pengguna Vape. Fungsi jargon pada komunitas Vape di Cinere terdiri dari 3 fungsi, yaitu fungsi instrumental, fungsi representasi, dan fungsi heuristik.

Saran dari penelitian ini berdasarkan implikasi penelitian dan keterbatasan penelitian di atas, adalah sebagai berikut :

Bagi pembaca, penelitian jargon pada komunitas Vape di Cinere dapat memberikan tambahan wawasan yang lebih luas mengenai penggunaan jargon. Pengunaan jargon ini menjadikan suatu identitas bagi para penggunanya dan juga dapat menciptakan suasana yang lebih akrab bagi kalangan profesi tersebut.

Dengan melakukan penelitian ini, penulis berharap dapat membuka peluang bagi peneliti selanjutnya untuk melakukan penelitian terhadap bentuk-bentuk jargon lainnya dan semoga penelitian ini menjadi acuan untuk bisa meneruskan penelitian ini dengan teori yang berbeda namun tetap menggunakan objek yang sama. Penelitian hanya memfokuskan pada jargon meskipun sebenarnya masih banyak yang dapat dikaji lebih dalam lagi. 


\section{DAFTAR PUSTAKA}

\section{Sumber Buku:}

Allan, K. and Kate, Burridge. 2006. Forbidden Words: Taboo and the Censoring of language. Cambridge: Cambridge University Press.

Alwasilah, Chaedar. 2012. L Linguistik Suatu Pengantar. Bandung: Angkasa.

Arikunto, Suharsimi. 1998. Prosedur Penelitian Suatu Pendekatan Praktek. Jakarta: Rineka Cipta.

Aslinda dan Leni Syafyahya. 2007. Pengantar Sosiolinguistik. Bandung: Refika Aditama.

Chaer, Abdul dan Leonie Agustina. 2010. Sosiolinguistik Perkenalan Awal. Jakarta: PT. Rineka Cipta.

Chaer, Abdul dan Leonie Agustina. 2004. Sosiolinguistik Perkenalan Awal. Jakarta: Rineka Cipta.

Chaer, Abdul. 2003. Linguistik Umum. Jakarta: PT. Rineka Cipta.

Departemen Pendidikan dan Kebudayaan. 1995. Teori dan Metode Sosiolinguistik II. Jakarta: Depdikbud.

Djajasudharma, Fatimah. 2006. Metode Linguistik Ancangan Metode Penelitian dan Kajian. Bandung : PT Refika Aditama.

Halliday, M.A.K dan Hasan Ruqaiya. 1994. Bahasa, Konteks dan Teks. Yogyakarta: Gadjah Mada University Press.

https://www.dosenpendidikan.co.id/pengertian-komunitas-menurut-para-ahli/ diakses pada hari Minggu, 20 Oktober 2019, Pukul 09:30 WIB.

https://www.kompasiana.com/helmi94628/5d2970370d823072691ce2b2/mengenal-vape-dan-sejarahvape-di-indonesia diakses pada hari Minggu, 20 Oktober 2019, Pukul 09:30 WIB.

Moleong, Lexy. 2002. Metodologi Penelitian Kualitatif. Bandung: PT. Remaja Rosdakarya.

Nababan. 1993. Sosiolinguistik: Suatu Pengantar. Jakarta: PT Gramedia.

Pateda, Mansur. 1987. Sosiolinguistik. Bandung: Angkasa.

Rokhman, Fathur. 2013. Sosiolinguistik; Suatu Pendekatan Pembelajaran Bahasa dalam Masyarakat Multikultural. Bandung: Graha Ilmu.

Santoso, Joko. 2003. Pengantar semantik bahasa Indonesia. Diktat pegangan kuliah semantik. Yogyakarta: FBSUNY.

Soeparno. 1993. Dasar-dasar Linguistik. Yogyakarta: PT. Mitra Gana Widya.

Sudaryanto. 1993. Metode dan Aneka Teknik Analisis Bahasa. Yogyakarta: Duta Wacana University Press.

Sumarsono dan Paina Partana. 2004. Sosiolinguistik. Yogyakarta: Pustaka Pelajar.

\section{Sumber Jurnal:}

Garing, Jusmianti. 2017. "Penggunaan Jargon Oleh Komunitas Waria Di Jejaring Sosial Facebook". Sulawesi Selatan : Jurnal Kajian Bahasa. Vol 6, No. 1.

Julianti, Ulfah. 2015. "Pemakaian Jargon Pada Dinas Perhubungan Kota Tangerang Selatan". Tangerang Selatan : Jurnal Sasindo Unpam. Vol 2, No. 2. 
Oktavia, Wahyu. 2018. "Variasi Jargon Chatting Whatsapp Grup Mahasiswa Tadris Bahasa Indonesia". Surakarta : Jurnal KATA. Vol 2, No. 2.

Sari, Indah. 2018. "Jargon Pada Grup WhatsApp Ladies Bikers Indonesia" : Jurnal Sasindo Unpam. Vol 6. No. 2.

Suminar, Mentari. 2018. "Jargon Jual Beli Online Dalam Media Sosial Instagram" (Kajian Sosiolinguistik). Kediri : Artikel Skripsi Universitas Nusantara PGRI Kediri. 